\title{
O USO DE TECNOLOGIAS CAD PARA (RE)CONHECER O PATRIMÔNIO BRASILEIRO EM RISCO DE DESAPARECIMENTO: A REMONTAGEM DIGITAL DO CHALÉ DE FERRO BELGA DESMONTADO NA DÉCADA DE 1980

\author{
THE USAGE OF CAD TECHNOLOGIES TO RECOGNIZE THE BRAZILIAN HERITAGE AT RISK \\ OF DISAPPEARANCE: THE DIGITAL ASSEMBLY OF THE BELGIAN IRON CHALET \\ DISASSEMBLED SINCE THE 1980'S
}

\author{
Flávia Olegário Palácios ${ }^{1}$, Thais Alessandra Bastos Caminha Sanjad ${ }^{2}$
}

\section{RESUMO:}

A Arquitetura de Ferro no Brasil caracteriza-se por edifícios metálicos, importados da Europa nos séculos XIX e XX, e faz parte da paisagem de diversas cidades, inclusive Belém (Pará). Belém possui vários edifícios inteiramente metálicos, inclusive os três únicos chalés de ferro provenientes da fábrica belga Forges D’Aiseau no país, que podem ser desmontados e remontados em função do seu sistema construtivo. Os chalés foram desmontados na década de 1980 em função de modificações urbanas, antes de possuírem proteção legal. Dois dos chalés foram restaurados e remontados, e um permanece desmontado, com peças suscetíveis ao intemperismo. 0 objetivo deste artigo é propor subsídios para a salvaguarda do chalé desmontado, por meio de pesquisa documental e projeto de remontagem para reconstitui-lo virtualmente, a fim de subsidiar ações de restauro e futura remontagem. A abordagem metodológica seguiu duas fases: 1) Pesquisa documental (pesquisa sobre o sistema construtivo, histórica e iconográfica; levantamento físico-cadastral e mapeamento de danos); 2) Projeto de remontagem (projeto de remontagem bidimensional e remontagem virtual tridimensional). Como resultados, foram documentadas 1.753 peças de diversos tipos, dimensões e estado de conservação, organizadas em fichas documentais e desenhos bidimensionais e tridimensionais. Assim, foram contabilizadas as peças que poderiam ser reutilizadas no projeto de remontagem, levando em consideração eventual remontagem real. O projeto de remontagem incluiu: plantas, cortes, elevações e mapa de peças. Por fim, foi desenvolvido o modelo tridimensional a partir do projeto de remontagem, resgatando a leitura do chalé.

PALAVRAS-CHAVE: arquitetura de ferro; chalé de ferro belga; remontagem virtual; conservação e restauro.

\begin{abstract}
:
Iron Architecture in Brazil is characterized by metallic buildings, imported from Europe in the 19th and 20th centuries, and is part of the landscape of several cities, including Belém (Pará). Belém has several metallic buildings, including the only three iron chalets from the Belgian factory Forges D'Aiseau in the country, which can be disassambled and reassembled due to their construction system. The chalets were disassambled in the 1980s due to urban modifications, before being legally protected. Two of the chalets have been restored and reassembled, and one remains disassambled, with parts susceptible to weathering. The purpose of this article is to propose subsidies for the safeguarding of the disassembled chalet, through documental research and reassembly project to virtually reconstruct the building, in order to subsidize restoration and future reassembly actions. The methodological approach followed two phases: 1) Documentary research (research about the constructive system, historical and iconographic data; architectural documentation and alteration mapping); 2) Reassembly project (bidimensional reassembly project and three-dimensional virtual reassembly). As result, 1.753 pieces of various types, dimensions and state of conservation were documented, organized in documental sheets and twodimensional and three-dimensional drawings. Thus, the parts that could be reused in the reassembly project were counted, taking into account an actual reassembly. The reassembly project included: plans, cuts, elevations and parts maps. Finally, the three-dimensional model was developed from the reassembly project, rescuing the image of the chalet.
\end{abstract}

KEYWORDS: Iron architecture; iron Belgian chalet; virtual reassembly; conservation and restoration.

How to cite this article:

PALÁCIOS, F.O.; SANJAD, T.A.B.C. Título do Artigo. O uso de tecnologias CAD para (re)conhecer o patrimônio brasileiro em risco de desaparecimento: a remontagem digital do chalé de ferro belga desmontado na década de 1980. Gestão \& Tecnologia de Projetos. São Carlos, v16, n3, 2021. https://doi.org/10.11606/gtp.v16i3.178008
Fonte de Financiamento: Universidade Federal do Pará (UFPA); Coordenação de Aperfeiçoamento de Pessoal de Nível Superior (CAPES); Conselho Nacional de Desenvolvimento Científico e Tecnológico (CNPQ).

Conflito de Interesse: Não há conflito de interesses

Ética em Pesquisa:

Não há necessidade.

Submetido em: 15/09/2020 Aceito em: 07/05/2021 


\section{INTRODUÇÃO}

Os estudos acerca da remontagem do chalé de ferro belga desmontado em Belém (PA, Brasil) faz parte de uma pesquisa mais abrangente, desenvolvida desde 2007 pelo Laboratório de Conservação, Restauração e Reabilitação (LACORE) da Universidade Federal do Pará (UFPA), sobre a Arquitetura de Ferro na capital paraense, seu reconhecimento patrimonial e valores atribuídos; sua materialidade, no que tange a ligas metálicas, tintas e produtos de alterações; e processos restaurativos.

A primeira etapa da pesquisa sobre o chalé desmontado foi voltada para o trabalho de conclusão de curso, intitulado "Antigo chalé da Imprensa Oficial do Estado do Pará: montagem, restauro e reutilização" (PALÁCIOS, 2009), abrangendo as características formais arquitetônicas do chalé desmontado, incluindo documentação, projeto de restauro e remontagem virtual. A segunda etapa foi vinculada à dissertação de mestrado, de título "Estudo tecnológico do chalé IOEPA: subsídios para a salvaguarda da arquitetura de ferro" (PALÁCIOS, 2011), voltada para a análise de estruturas para futura remontagem e confecção de réplicas, identificação das ligas metálicas e produtos de intemperismo, a fim de subsidiar o restauro científico desse edifício tão significativo da arquitetura de ferro. A terceira etapa, na tese de doutorado, de título "Dos minerais aos materiais de arquitetura e processos de degradação: edifícios e ornamentos metálicos dos séculos XIX e XX" (PALÁCIOS, 2015), versa sobre o estudo de ligas metálicas de outras proveniências e comparação com as do chalé desmontado, bem como diversos produtos de alteração em ligas ferrosas em climas amazônicos.

A Arquitetura de Ferro faz parte do patrimônio histórico edificado de diversas cidades do Brasil, inclusive Belém, capital do Estado do Pará, região Norte. Essa tipologia arquitetônica caracteriza-se por edifícios metálicos, importados para terras brasileiras no fim do século XIX e início do XX, para suprir a demanda das grandes transformações pelas quais diversas cidades estavam passando, aliando novos materiais e tecnologias vigentes na Europa (SILVA, 1986; KUHL, 1998; PALÁCIOS, 2011).

No fim do século XIX e início do XX, a cidade de Belém passava pelo período do Ciclo da Borracha, também conhecido como Belle Époque, em que o capital inglês e os costumes franceses permearam desde a arquitetura até os modos de viver da burguesia paraense (DERENJI, 1993; SARGES, 2010). Foram importados de diversas fábricas europeias, principalmente, da Inglaterra, da Escócia, da Alemanha e da Bélgica (SILVA, 1986), vários elementos em ferro aplicados na arquitetura, desde bens integrados em fachada, mobiliários urbanos, componentes estruturais e até mesmo edifícios inteiramente metálicos para a cidade, conhecidos como "Arquitetura de ferro" (SILVA, 1986), dentre eles reservatórios de água, galpões, e mercados, até hoje presentes na paisagem da cidade.

Tais bens metálicos eram comercializados a partir de catálogos variados, com alternativas diversas para satisfazer o gosto do cliente, sendo importante artifício mercadológico (SILVA, 1986). Os catálogos foram um dos principais responsáveis pela difusão das peças de ferro fundido no mundo, nas quais as peças eram desenhadas detalhadamente e apresentavam toda a linha de seus produtos, permitindo ao comprador fácil visualização na hora de escolher e fazer combinações (COSTA, 2001).

Os edifícios da arquitetura de ferro em Belém eram majoritariamente importados a partir da iniciativa pública, encomendados pelo governador da época, Augusto Montenegro (19011909) e o intendente Antônio Lemos (1897-1910) (PALÁCIOS, 2011). Apesar das importações de cunho privado serem mais voltadas para bens integrados em fachada, Belém também possui edifícios inteiramente metálicos importados para uso privado, que são os três 
chalés, provenientes da fábrica belga Forges D’Aiseau, únicos no Brasil (SILVA, 1986). Os chalés foram importados por membros da elite da borracha, a fim de distinguir camadas sociais por meio da arquitetura, em particular pela novidade das construções em ferro (DERENJI, 1993).

Tais edifícios foram construídos segundo o sistema Danly, que consiste na utilização do ferro como material quase exclusivo na construção, presente nas estruturas, paredes, forros e telhas. É um sistema essencialmente industrial e estandardizado, em que todos os elementos arquitetônicos são feitos por meio de gabaritos e prensas, e poderiam ser montados de diversas formas, inclusive desmontados e remontados em locais diferentes (SILVA, 1986; KUHL, 1998; PALÁCIOS, 2011). Os edifícios construídos segundo esse sistema dão a impressão de serem uma caixa bem fechada com paredes compostas por chapas, que distavam entre si um espaço considerável para que se sustentassem firmemente, e prover isolamento térmico e ventilação (SILVA, 1986).

Dois dos chalés foram montados em área afastada do centro da cidade e o terceiro em local mais central. Inicialmente possuíam uso residencial, mas no decorrer dos anos adotaram-se usos diversos em função das modificações ocorridas na cidade (PALÁCIOS, 2011). Em momento de muitas mudanças urbanas, os chalés foram desmontados na década de 1980, para serem substituídos por edificações contemporâneas, com o intuito de serem remontados em outras localidades. As peças dos três chalés foram armazenadas no Bosque Rodrigues Alves onde ficaram no aguardo de remontagem. Enquanto desmontados, os três chalés foram tombados à nível estadual.

Dois dos três chalés foram restaurados, remontados e requalificados no início da década de 1990: um na Universidade Federal do Pará (UFPA) e o outro no Bosque Rodrigues Alves. Entretanto, o chalé pertencente à Imprensa Oficial do Estado do Pará (IOEPA) foi desmontado e permanece no aguardo de remontagem, há mais de trinta anos (Figura 1).

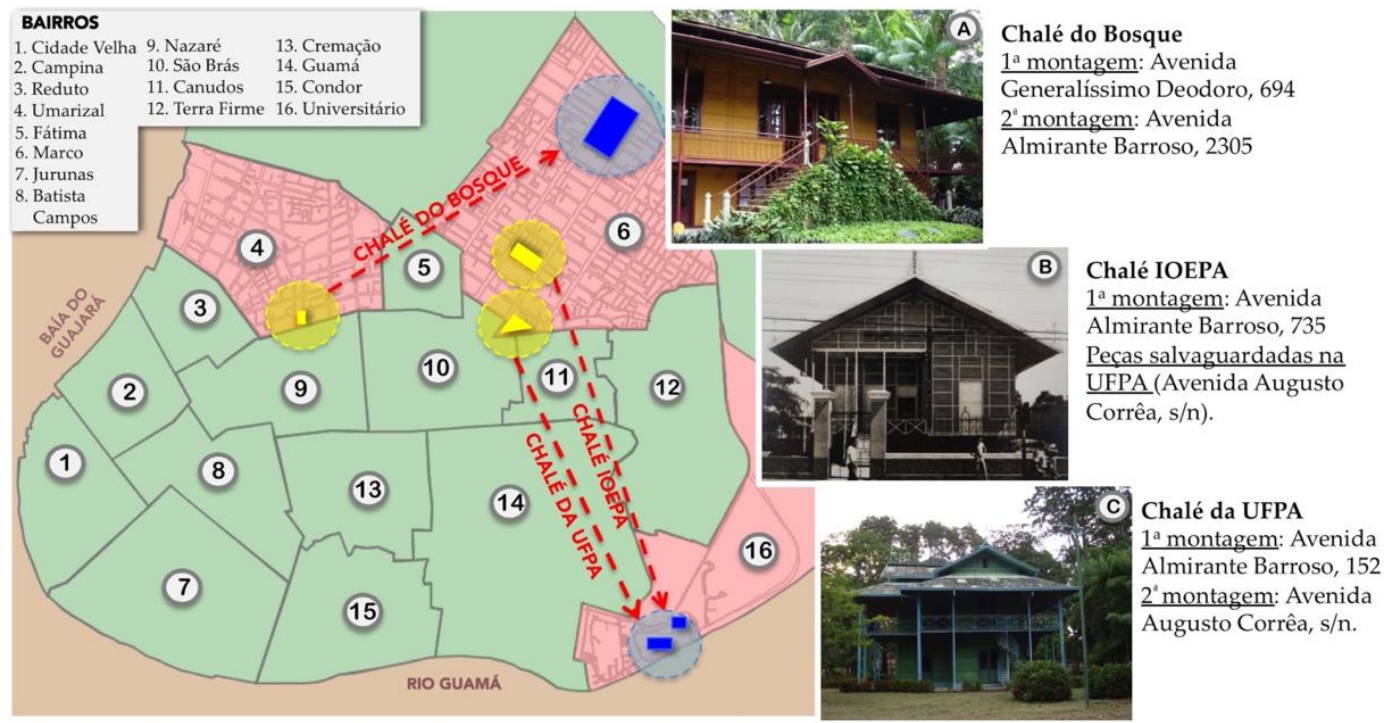

Mesmo possuindo valor histórico, tecnológico, social e arquitetônico, muitos dos edifícios metálicos e várias outras estruturas importados não existem mais, não tendo sido poupados nos diversos processos de grandes transformações pelos quais passam várias cidades brasileiras (PALÁCIOS, 2011). Foram desmontados e as peças perdidas, descartadas, ou furtadas. Além dos problemas de reconhecimento que alguns edifícios provenientes da industrialização sofrem (KUHL, 2008), a conservação do ferro em climas úmidos é um desafio, ao passo que a corrosão afeta rapidamente as ligas ferrosas históricas.
Figura 1. Mapa esquemático indicando a localização da: 1) primeira montagem dos chalés, na cor amarela; 2) segunda montagem dos chalés do Bosque e UFPA, e local de armazenamento das peças do chalé desmontado, em azul.

Fonte: Elaborado pelas autoras - Fotografias do Chalé do Bosque (A) e Chalé da UFPA (B) feitas pelas autoras; Fotografia do Chalé IOEPA (C) disponível em PONTES, REIS, DUARTE (1978). 
Há a necessidade de conservação constante, já que os produtos de corrosão passam por vezes despercebidos por baixo das camadas de tinta ou galvanização, quando apresentam falhas, observados em estudos metalográficos em edifícios e ornamentos históricos em ferro de Belém (PALÁCIOS, ANGÉLICA, SANJAD, 2014; PALÁCIOS, 2015). Além do intemperismo, os metais históricos em Belém também são alvo de diversas ações antrópicas, como furtos, procedimentos de restauro e uso inadequados.

Nesse contexto, o chalé IOEPA, exemplar único da arquitetura de ferro, infelizmente, ainda está desmontado e no aguardo de futura remontagem e reestruturação da sua leitura como patrimônio histórico edificado (PALÁCIOS, 2011). A ausência de remontagem gerou várias notícias nos jornais da época, que enfatizavam o valor patrimonial do chalé e o descaso com as peças (O LIBERAL, 1991), com estruturas visivelmente corroídas. Após solicitação de remanejamento dos componentes do edifício do Bosque Rodrigues Alves, em função dos visíveis sinais de corrosão, estes foram guardados no campus de Belém da UFPA em 1991 (Figura 2)

Figura 2. Chalé IOEPA montado na década de 1970

(A) e peças do chalé no Campus Belém da UFPA após desmontagem (B).

Fonte: Fotografia do Chalé IOEPA montado (A) disponível em PONTES, REIS, DUARTE (1978); Fotografias do chalé desmontado (B) feitas pelas autoras.

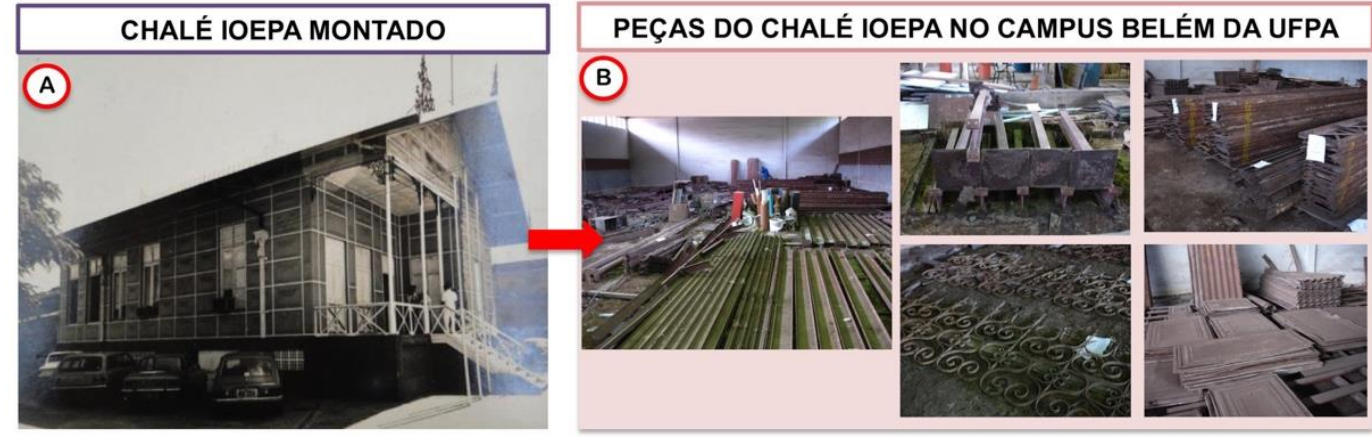

Possivelmente o chalé IOEPA foi o primeiro a chegar em Belém dentre os três chalés, pois apresenta versão mais simples do sistema construtivo (SILVA, 1986), com a ausência de algumas peças que promovem ventilação e desenho mais simples das vedações (chapas estampadas). De acordo com as prospecções pictóricas, o chalé desmontado apresentava artifício estético também a partir do uso de tintas, que apresentam variação de cores de acordo com o desenho da chapa, em rosa e bege (PALÁCIOS, 2011).

Em 1993, foi realizada a avaliação das peças pelos arquitetos Geraldo Gomes da Silva, Maria Beatriz Faria e José Morgado. No entanto, até hoje as peças permanecem no aguardo de remontagem. Assim, houve a necessidade de reavaliar o estado de conservação dos componentes do edifício e estudar a viabilidade de remontagem.

O objetivo deste artigo é propor subsídios para a salvaguarda do chalé IOEPA, o chalé desmontado, por meio de pesquisa documental e projeto de remontagem para reconstituir virtualmente o edifício, com o intuito de subsidiar ações de restauro e futura remontagem e requalificação, a fim de preservar a memória da arquitetura de ferro residencial de Belém.

A importância da documentação do patrimônio arquitetônico é inegável e imprescindível face ao risco e à degradação em que se encontram alguns edifícios, e é importante ferramenta para a sua conservação (PALÁCIOS, 2011). A documentação digital de construções históricas serve para organizar dados e informações existentes acerca do monumento, tornando, assim, seu processo de conservação mais eficaz.

A documentação tridimensional contribui, também, para melhor interpretação das características dos monumentos, a reconstituição da sua forma, bem como gera informações espaciais mais precisas (WILSON et al, 2017; BERNARDI et al, 2019). É uma ferramenta importante aplicada em diversos projetos de conservação do patrimônio construído nas 
últimas duas décadas (GOMES, BELLON, SILVA, 2014) e favorece a perpetuação do conhecimento sobre esses tipos de construção.

A recuperação do chalé desmontado é muito importante não só para a preservação do edifício histórico, mas também para a preservação da história da arquitetura metalúrgica. Os edifícios representantes da arquitetura do ferro são testemunhos relevantes do desenvolvimento da história, da técnica, de métodos construtivos e da estática. Essas edificações trazem, em sua concepção, inovações formais, espaciais e tecnológicas que devem ser preservadas (KUHL, 1998; 2008).

\section{ABORDAGEM METODOLÓGICA}

A abordagem metodológica seguiu duas fases sequenciais: 1) pesquisa documental do chalé desmontado e 2) Projeto de remontagem (Figura 03). A primeira fase compreende as etapas referentes ao conhecimento e documentação do edifício, abrangendo: A) estudo sobre o sistema construtivo; B) pesquisa histórica e iconográfica; e C) levantamento físico-cadastral e mapeamento de danos das peças do chalé, etapa mais longa da pesquisa. A segunda fase compreende as etapas: D) projeto de remontagem e E) remontagem virtual. As etapas estão descritas de forma esquemática a seguir na Figura 03.

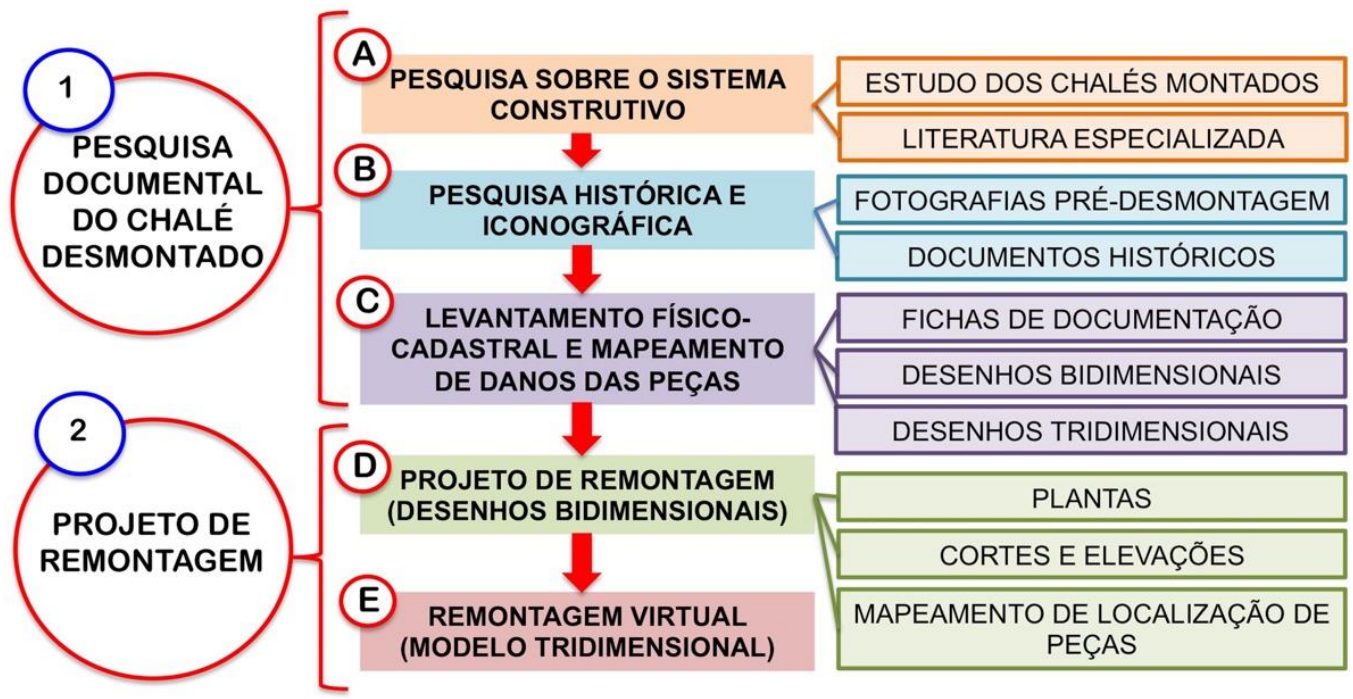

A pesquisa documental do chalé desmontado iniciou-se a partir do estudo preliminar dos chalés montados, que incluiu fotografias, desenhos esquemáticos e virtualizações; e o estudo sobre o sistema Danly na literatura (etapa A). Depois se deu início ao estudo histórico e iconográfico do chalé desmontado enquanto montado, em jornais e fotografias da época (etapa B).

Assim, foi iniciada a etapa C, de levantamento físico-cadastral e mapeamento de danos das peças, com a confecção de ficha de documentação a ser utilizada para a organização de dados. A ficha de documentação abrange as seguintes informações sobre as peças: localização (endereço, município, unidade federativa, local de armazenamento e responsável imediato), identificação (número, número de peças iguais, procedência, autoria, material/técnica, parte da edificação, função, estilo e dimensões), descrição (características específicas arquitetônicas), levantamento fotográfico, estado de conservação (especificação das alterações, em especial a corrosão, incluindo condições de aproveitamento) e localização da peça na montagem virtual tridimensional (PALÁCIOS, 2011). A ficha documental foi testada em campo e corrigida a partir das necessidades observadas.
Figura 3. Fluxograma esquemático da abordagem metodológica da pesquisa

Fonte: Elaborada pelas autoras 
Após a formulação da ficha, foi realizada uma organização prévia, agrupando peças de tipos e dimensões semelhantes, para iniciar o levantamento físico-cadastral que gerou os desenhos bidimensionais. Essa etapa necessitou de organização do galpão em que as peças estavam armazenadas de forma a otimizar o trabalho. As peças de maiores dimensões já estavam previamente organizadas e as que não estavam foram organizadas em fileiras e colocadas sobre estrados de madeira, de modo a minimizar o avanço do processo de degradação pelo contato com o solo.

Prosseguiu-se o trabalho com a numeração e a contagem das peças, tendo o espaço sido dividido em 09 áreas para facilitar a organização dos dados, de acordo com função das peças, entre peças de cobertura (Área 1); perfis de menor dimensão e guarda-corpos (Área 2); vedações (Área 3); ornamentos (Área 4); outros materiais não pertencentes ao chalé, que não puderam ser remanejados (Área 5), treliças (Área 6); pilares, calhas, tesouras, canos e mãofrancesas (Área 7); perfis de maior dimensão (Área 8); pilares externos ao galpão (Área 9) (PALÁCIOS, 2011).

Cada área foi dividida em fileiras para numeração das peças, a fim de facilitar a organização dos dados coletados. Cada peça possui três grupos de números: o primeiro relativo a área, o segundo a fileira, e o terceiro à localização na fileira. Por exemplo, a peça 7.2.1 pertence à área 7, localizada na fileira 2 e é a peça número 1 da fila (PALÁCIOS, 2011). Todas as peças foram marcadas com tinta branca segundo a numeração pré-estabelecida.

As fichas foram preenchidas a medida que os dados foram coletados, concomitantemente ao levantamento fotográfico e físico-cadastral de cada peça. Todas as peças foram fotografadas em ao menos 04 ângulos, permitindo o registro do seu real estado de alteração durante o levantamento, sendo possível documentar vários aspectos como: geometria aproximada dos objetos, detalhes arquitetônicos, parafusos, encaixes das peças, texturas e alterações intempéricas e antrópicas.

Foram coletadas informações relativas ao comprimento, largura, espessura, localização e dimensão de furos para rebites e parafusos, e ornamentações para o desenvolvimento dos desenhos bidimensionais de cada peça por meio da medição direta, com o intuito de gerar os produtos gráficos, contendo informações essenciais para restituições de edificações e futuras intervenções, permitindo a visualização de diversos detalhes, facilitando o planejamento de eventuais alterações a serem executadas (OLIVEIRA, 2008). Foram também coletados dados referentes às alterações intempéricas e antrópicas presentes nas peças, representadas no mapeamento de danos.

As informações métricas foram digitalizadas no AutoCAD em desenhos bidimensionais e tridimensionais das peças. A tecnologia CAD foi empregada para a reconstituição virtual por ser uma ferramenta qualificada de análise para a reconstrução do chalé, pois possui precisão geométrica, é acessível, de baixo custo e possui flexibilidade de aplicações (STYLIADIS et SECHIDIS, 2011). A referida ferramenta, também, permite a visualização tridimensional, contribuindo para a interpretação espacial e temporal, e o vislumbre de diferentes hipóteses construtivas, de modo a assegurar melhor compreensão do monumento.

Nas fases da pesquisa documental do chalé desmontado e projeto de remontagem, iniciadas em 2007 e 2008, respectivamente, a pesquisa ainda não contava com nenhum aporte financeiro, e foi desenvolvida por uma equipe bem reduzida, de três pessoas. Dessa forma, o AutoCAD foi empregado por ser de mais fácil disponibilidade, já que os recursos eram escassos.

Os desenhos bidimensionais das peças foram dispostos em pranchas tamanho A4, na segunda folha da ficha cadastral, organizados da seguinte maneira: a primeira parte da prancha é reservada aos desenhos cadastrais da peça de como era originalmente, e a segunda parte é 
reservada aos desenhos com o mapeamento de danos. Para cada peça também foi desenvolvido o modelo tridimensional, por meio do AutoCAD, visando prover subsídios para a remontagem virtual do chalé.

Assim, foi iniciada a Fase 2, o projeto de remontagem. A partir da finalização da representação bidimensional e tridimensional de todas as peças, foi iniciado o processo do desenhos das plantas, cortes e elevações e o mapeamento de localização de cada peça no projeto. Os desenhos foram feitos de forma concomitante, baseados nas informações das etapas anteriores, e geraram o modelo tridimensional de remontagem virtual.

\section{RESULTADOS}

A partir do estudo preliminar do sistema Danly e iconografia antiga de quando o chalé estava montado, foi possível identificar, de forma geral, as peças constituintes e suas possíveis localizações, formas e proporções, bem como entender melhor a estrutura do edifício. Não foram encontradas informações acerca do levantamento físico-cadastral feito na década de 1990, portanto, para o projeto de remontagem e reconstrução virtual foram utilizadas iconografias antigas do chalé desmontado.

Apesar da extensa pesquisa histórica, feita em documentos dos séculos XIX e XX, não foram encontrados registros referentes ao processo de montagem dos chalés na sua primeira implantação, nem instruções de montagem. Portanto, não foi possível definir com exatidão o número de peças da primeira montagem em Belém, apenas os diferentes tipos e uma estimativa de quantidade de cada tipo de peça por meio de iconografia.

Observou-se que o chalé desmontado recebeu, ao longo dos anos, a inserção de alguns bens integrados, como as grades ornamentais em ferro forjado nos beirais e cumeeira, de formato semelhante a grades produzidas localmente pelo Instituto Lauro Sodré; e um duto vertical de ferro fundido da fundição escocesa W. MacFarlane \& Co.

Durante a experiência do estudo do chalé desmontado, foi realizada a documentação e modelagem tridimensional do Chalé do Bosque, etapa importante para o entendimento do sistema construtivo. Apesar do Chalé do Bosque ser um exemplar mais "novo", que apresenta maior variedade de peças, a sua documentação detalhada auxiliou bastante o projeto de montagem do chalé desmontado. Para o Chalé da UFPA, foram realizados desenhos esquemáticos.

A partir do processamento e da organização de todas as informações obtidas na documentação do chalé desmontado, foi possível contabilizar o número de peças existentes durante a pesquisa: 1.753 (mil setecentos e cinquenta e três), dentre peças estruturais, de vedação e ornamentação (PALÁCIOS, 2011). Para cada peça foram desenvolvidas fichas documentais, desenhos bidimensionais e modelos tridimensionais, que posteriormente, foram quantificadas e inseridas no projeto de remontagem.

Durante o desenvolvimento dos desenhos, foi possível entender melhor a estrutura do chalé, no que se refere às formas dos componentes arquitetônicos e às suas dimensões exatas; a localização de furos para o encaixe das peças; e a frequência das alterações intempéricas e antrópicas. A partir dos modelos geométricos foi possível entender melhor a volumetria das peças, como elas se encaixam para formar a estrutura da construção e a função que elas exercem no edifício.

Vale ressaltar que foram utilizadas no projeto apenas as peças que são passíveis de reutilização, a partir da avaliação do estado de conservação. Algumas, infelizmente, não poderão ser reutilizadas em função do processo corrosivo avançado, que causa lacunas, perda de espessura e fragilidade nas peças (FONTINHA e SALTA, 2007). 
Observou-se que $100 \%$ das peças do chalé apresentam produtos de corrosão, variando do mais superficial ao mais profundo, e 7,9\% apresentam maior agravamento em função do avanço da corrosão já com presença de lacunas significativas. Dentre as peças mais alteradas, estão os pilares e tesouras, que não foram reaproveitadas no projeto de remontagem. As demais peças, como as chapas de vedação, ornamentos, calhas e cumeeiras, foram aproveitadas o máximo possível dentro das possibilidades, relativas à integridade do material.

Algumas peças de vedação ainda apresentam remanescentes de camadas de tinta, que de certa forma promovem, mesmo que não totalmente, a conservação das peças. 0 processo corrosivo em ligas ferrosas é constante e acelerado, especialmente em climas úmidos, e as camadas de tinta são essenciais na proteção do ferro fundido (PALÁCIOS, ANGÉLICA E SANJAD, 2014). As demais peças não apresentam nenhuma camada de tinta ou proteção em que foram também verificados produtos de corrosão mais intensos.

Além das peças corroídas e não passíveis de reutilização, notou-se, ao fim do levantamentofísico cadastral, que algumas peças estavam faltando, provavelmente perdidas no processo de desmontagem e transporte, para as quais serão necessárias réplicas. Mas algumas outras peças "sumiram" no decorrer da pesquisa, correspondentes às cabeças de dutos verticais ornamentais da W. MacFarlane \& Co e perfis "I" de $68 \mathrm{~cm}$ de altura. Os perfis já tinham sido registrados e desenhados em formato bidimensional e tridimensional, mas os dutos verticais não foram documentados, e possivelmente foram furtados em função do valor estético e histórico (Figura 04).
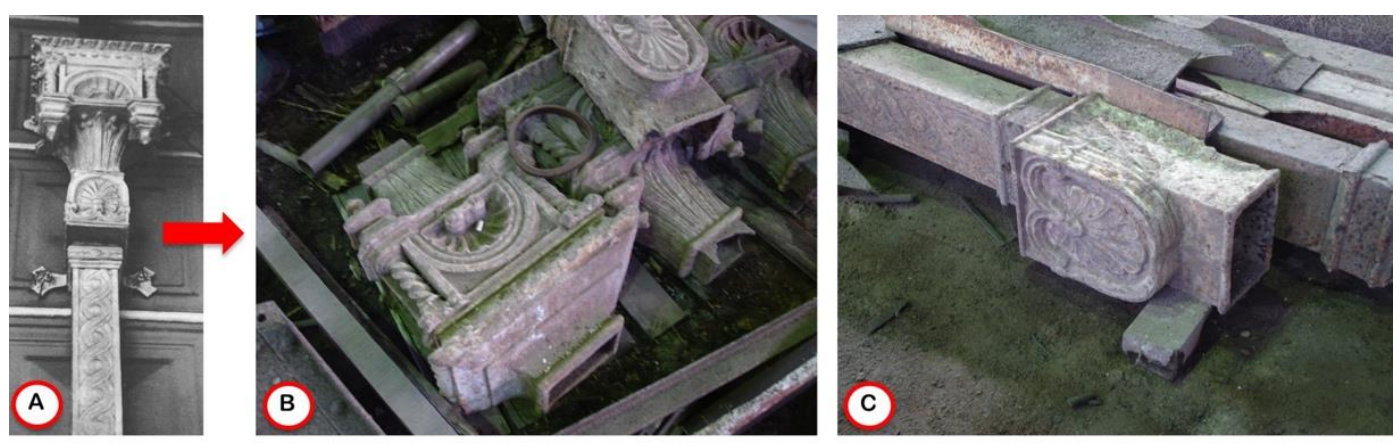

Em relação às cabeças dos dutos verticais, as mesmas só tinham sido fotografadas à altura do sumiço, representando uma lacuna na pesquisa e na história do patrimônio proveniente da industrialização. Entretanto, os dutos da W. MacFarlane's e Co são ainda muito presentes em fachadas de construções históricas de Belém, e foram objeto de pesquisa documental, desenvolvida a partir de 2015 pelo Laboratório de Conservação, Restauração e Reabilitação (LACORE), em diversos bairros da cidade. Felizmente, os modelos de corpo, braçadeira e cabeça do duto vertical presente no chalé foram encontrados em algumas fachadas documentadas, e atualmente passam por processo de virtualização, assim, possibilitando a confecção de uma eventual réplica.

Apesar das peças do chalé terem sido feitas por processos industrializados, e geralmente serem atribuídas características seriadas e repetidas, elas ainda apresentam diferenças entre si. Segundo Viñas (2005), as peças industrializadas ainda guardam na sua microestrutura diferenças, já que os processos industriais em materiais históricos não eram exatos, o que atribui características únicas para cada peça, ainda que pareçam iguais.

Infelizmente, há perdas nesse patrimônio esquecido, porém tão importante, e para a sua remontagem, será necessário tomar partido de réplicas. As peças que não puderem ser 
utilizadas, poderão ser restauradas, armazenadas e aguardarão sua inserção adequada em instituição de guarda.

\section{QUANTIFICAÇÃO DE PEÇAS}

Concluído o processamento dos desenhos e das fichas de todas as peças, foi possível quantificar aquelas que ainda poderiam ser reutilizadas em eventual remontagem, considerando o estado de conservação. Por mais que o chalé desmontado tenha estética mais simples que os outros, constatou-se que o mesmo possui grande diversidade de peças em tipo e dimensões.

Foram também quantificadas as réplicas necessárias, levando em consideração futura remontagem do chalé (Tabela 1). Optou-se por fazer réplicas de ferro fundido, seguindo preceitos de distinguibilidade (BRANDI, 2004) e as características das ligas descritas na análise tecnológica (PALÁCIOS, 2011; 2015) para as peças não estruturais, e aço para as estruturais, a serem futuramente especificadas em consultoria estrutural.

Nos grupos de pilares e tesouras, estes deverão ser substituídos em sua totalidade, em função do péssimo estado de conservação. As tesouras apresentavam-se em fragmentos, logo, os fragmentos foram contabilizados, mas possivelmente alguns pertenciam à mesma estrutura.

variedade e de peças o chalé para de es os, bem ero de ão utilizada le uantidade

rada pelas

\begin{tabular}{|c|c|c|c|c|}
\hline \multicolumn{5}{|c|}{ PEÇAS DO CHALÉ DESMONTADO } \\
\hline \multirow{2}{*}{$\begin{array}{c}\text { Tipo } \\
\text { De peça }\end{array}$} & \multirow{2}{*}{$\begin{array}{l}\text { Variedade de } \\
\text { dimensões }\end{array}$} & \multicolumn{2}{|c|}{ Quantidade de peças } & \multirow{2}{*}{$\begin{array}{l}\text { Quantidade } \\
\text { de réplicas }\end{array}$} \\
\hline & & Existentes & $\begin{array}{c}\text { Não passíveis de } \\
\text { utilização }\end{array}$ & \\
\hline Calhas & 03 & 12 & - & - \\
\hline Canos & 02 & 19 & - & - \\
\hline $\begin{array}{l}\text { Chapas de } \\
\text { vedação }\end{array}$ & 32 & 1.128 & 103 & 32 \\
\hline Cumeeiras & 01 & 09 & - & 01 \\
\hline Duto vertical & 01 & 01 & - & 01 \\
\hline $\begin{array}{l}\text { Grades } \\
\text { ornamentais }\end{array}$ & 09 & 62 & - & 54 \\
\hline $\begin{array}{l}\text { Guarda - } \\
\text { corpo }\end{array}$ & 02 & 03 & 06 & 01 \\
\hline Mão-francesa & 01 & 06 & 06 & - \\
\hline Perfis & 22 & 171 & 11 & 18 \\
\hline Pilares & 01 & 11 & 02 & 20 \\
\hline Telhas & 01 & 122 & 16 & 02 \\
\hline Tesouras & 01 & 16 & - & 08 \\
\hline Treliças & 15 & 193 & - & 18 \\
\hline
\end{tabular}

A partir da quantificação, foi possível iniciar a etapa do projeto de montagem, em desenhos bidimensionais, já levando em consideração ausência de várias peças e as réplicas.

\section{PROJETO DE REMONTAGEM E MODELAGEM TRIDIMENSIONAL}

0 projeto de remontagem inclui diversos desenhos, dentre plantas, cobertura, estruturas, forro, cortes, mapeamento de vedações (paredes internas e externas), e fachadas. Como não foram encontrados documentos detalhados ou manuais de montagem do chalé, levou-se em consideração as características do Sistema Danly (KUHL, 1998) e demais informações 
Figura 5. Planta do chalé desmontado.

Fonte: Elaborada pelas autoras
Título do Trabalho: O uso de tecnologias CAD para (re)conhecer o patrimônio brasileiro em risco de desaparecimento: a remontagem digital do chalé de ferro belga desmontado na década de 1980

encontradas na literatura para a definição de espaçamento entre peças, incluindo a organização interna do chalé.

O projeto de montagem não foi realizado da forma como antevisto no início do levantamento, já que esperava-se estrutura quase completa. Assim, tomou-se partido do sistema construtivo para a remontagem, adaptando a localização de peças para melhor aproveitamento, especialmente as vedações que compõem a caixa externa e forro do chalé. 0 uso apropriado é essencial para o edifício, dada a sua importância para a própria manutenção e, portanto, sobrevivência da construção, mas para o projeto de remontagem não era fator essencial no momento do trabalho. No caso do chalé desmontado, a preocupação inicial foi recuperar a sua forma, e em um estudo posterior será desenvolvida com mais detalhes a proposta de uso.

A primeira parte do projeto de montagem foi o desenho da planta (Figura 5) de aproximadamente $12 \mathrm{~m} \times 20 \mathrm{~m}$. A planta foi resultado dos estudos de iconografia histórica e desenhos antigos do chalé montado. Nesta fase foi determinada a dimensão do edifício, a disposição dos ambientes internos, a dimensão e localização das esquadrias, e a marcação dos pilares, baseadas na disposição de espaços de quando o chalé estava montado.

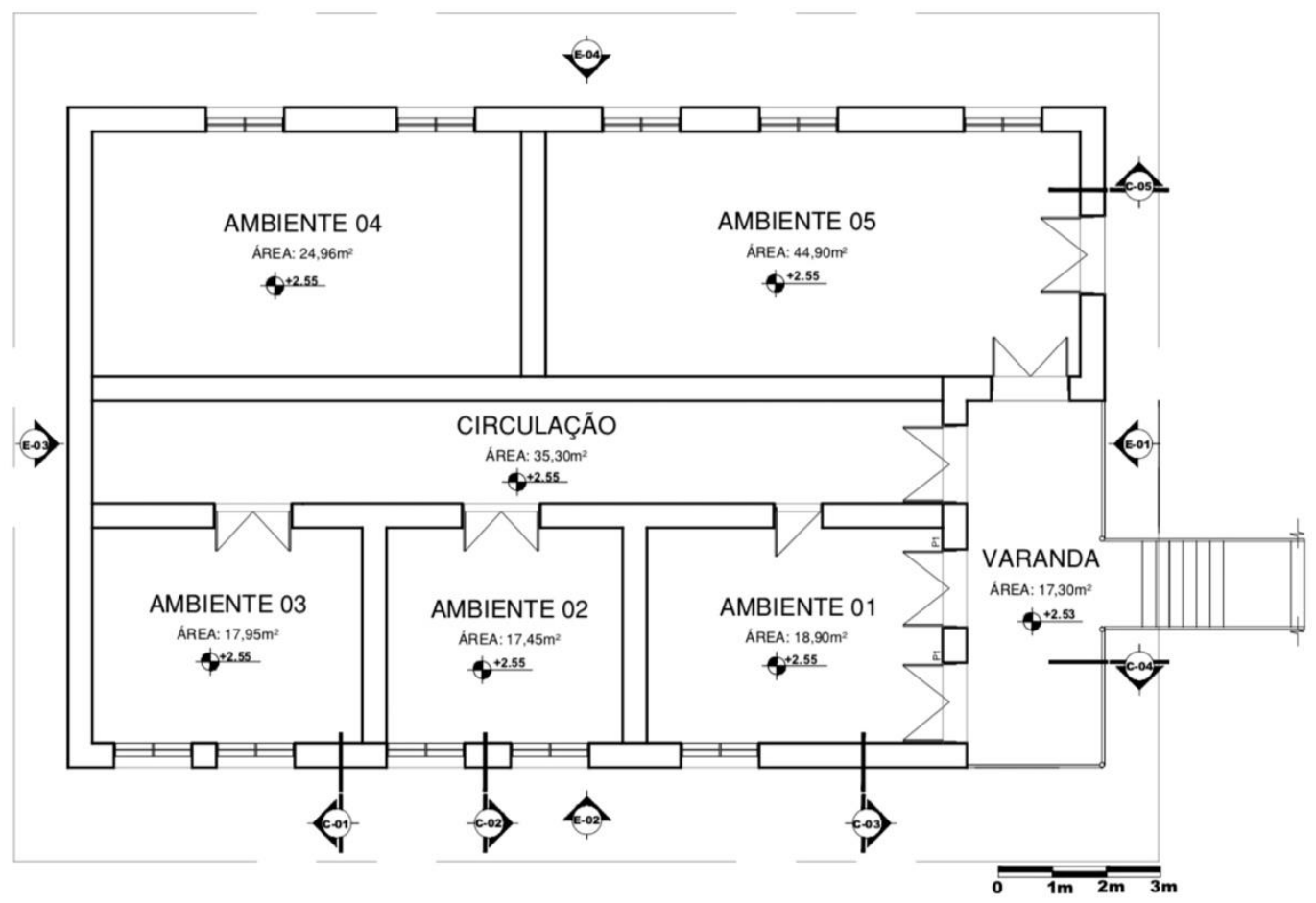

Em futura remontagem e proposta de novo uso, as paredes internas poderão ser adaptadas a partir do uso proposto, e ser de material contemporâneo adequado de espessura variada, ou réplicas, já que as peças originais passíveis de uso foram inseridas nas fachadas e forro. Algumas alterações foram feitas como dimensionamento de esquadrias, que seguiram desenho semelhante ao original, em madeira e vidro.

Para o projeto de remontagem, o foco principal foi a parte em ferro, logo, para o porão alto, existente quando o chalé estava montado, não foi feito o desenho da planta, por ser uma parte completamente adaptável a partir do uso a ser atribuído ao chalé futuramente. Assim, apenas foi reconstituída a leitura de uma caixa fechada para o porão alto, semelhante à forma de quando estava montado, e seguindo também o padrão do Chalé do Bosque, que possui porão alto em alvenaria. Foi inserido na montagem blocos de concreto abaixo dos pilares e degraus 
a mais na escada, de forma a aumentar o pé-direito do porão-alto em futura proposta, entretanto, tal inserção é reversível.

A planta de localização de pilares foi baseada nas demais plantas, que resultou também, no desenvolvimento dos cortes estruturais. A partir da localização dos pilares, foram locadas as vigas, treliças e, por último, as tesouras. Dessa forma, foi possível desenvolver os desenhos da cobertura, já que as distâncias das tesouras eram conhecidas, variando entre 3 e 5 metros. As terças foram localizadas entre as tesouras e as ripas a cada 1,90 metros, aproximadamente.

Com as plantas e a estrutura definidas, foi iniciada a montagem das fachadas, etapa mais trabalhosa do projeto de remontagem. No sistema Danly as paredes são ocas e compostas por duas faces de chapas estampadas, e no caso do chalé desmontado, distando $45 \mathrm{~cm}$. Todas as peças foram identificadas por meio das suas dimensões nos desenhos das fachadas e as esquadrias foram locadas segundo o ritmo que a edificação imprimia originalmente.

0 padrão de modulação utilizado no projeto de remontagem das fachadas não foi idêntico ao utilizado na montagem original do chalé (PALÁCIOS, 2011). O remanejamento das vedações foi viabilizado em função do sistema construtivo, que permite a combinação de chapas estampadas de acordo com a necessidade ou estética desejada na montagem do edifício. Vedações de dimensões específicas foram direcionadas para o forro, para diferenciação na leitura interna do edifício.

Optou-se por utilizar as peças originais em bom estado na caixa externa do edifício e forro, levando em consideração as duas faces das paredes ocas da edificação, com objetivo de reestabelecer a leitura do chalé. As réplicas (32) foram utilizadas na caixa externa e forro, conforme indicado na Figura 6.

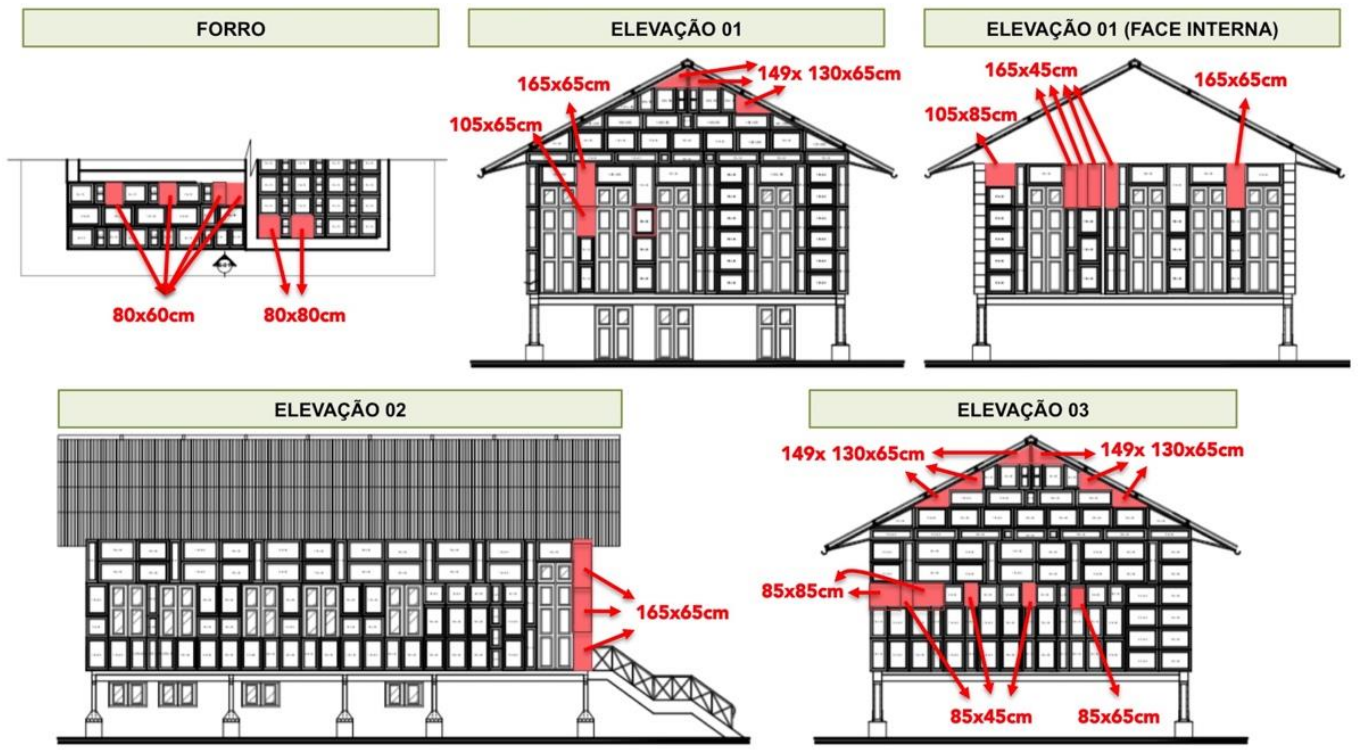

Por último foram colocadas as telhas, peças de cumeeira, calhas e dutos de escoamento vertical, e grades ornamentais, respectivamente, para o desenho completo das fachadas (Figura 7).
Figura 6. Desenhos esquemáticos da localização e dimensão das réplicas na caixa externa e forro do chalé

Fonte: Elaborada pelas autoras 
Figura 7. Fachadas 01 e 04 do projeto de remontagem

Fonte: Elaborada pelas autoras

Figura 8. Remontagem virtual (modelo tridimensional)

Fonte: Elaborada pelas autoras
Título do Trabalho: O uso de tecnologias CAD para (re)conhecer o patrimônio brasileiro em risco de desaparecimento: a remontagem digital do chalé de ferro belga desmontado na década de 1980
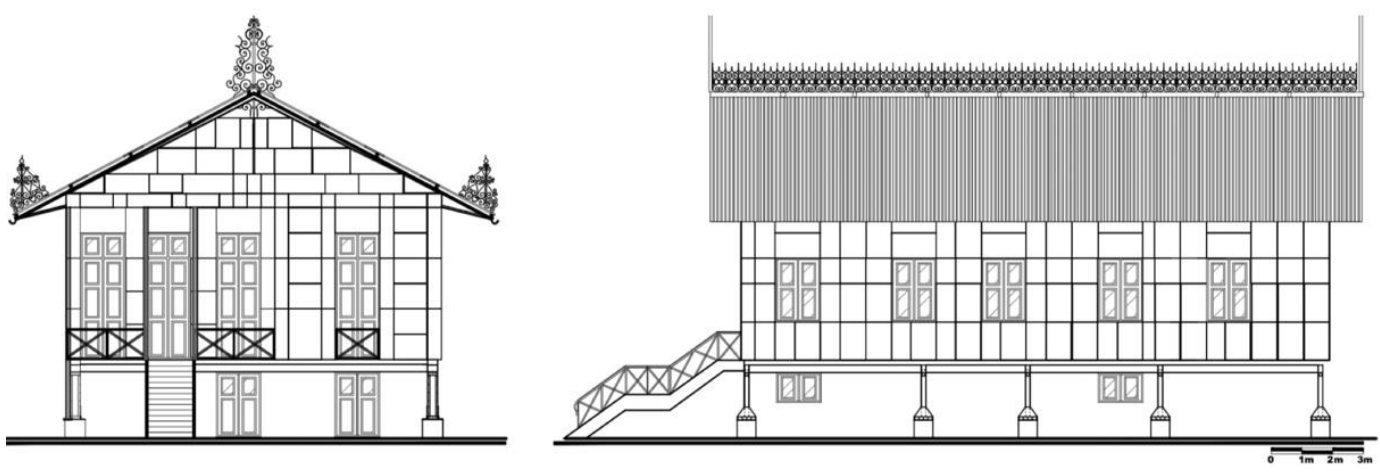

Com o projeto de remontagem finalizado, foi desenvolvido o modelo tridimensional do edifício. Algumas partes do modelo foram construídas juntamente com o projeto de montagem, e diversas alterações foram feitas no projeto durante a execução do modelo tridimensional, e vice-versa (PALÁCIOS, 2011). A possibilidade de verificação do modelo por meio do AutoCAD (Figura 8) foi imprescindível para a montagem virtual, já que foi possível observar as peças em todas as suas faces e estudar melhor o seu sistema de encaixe.
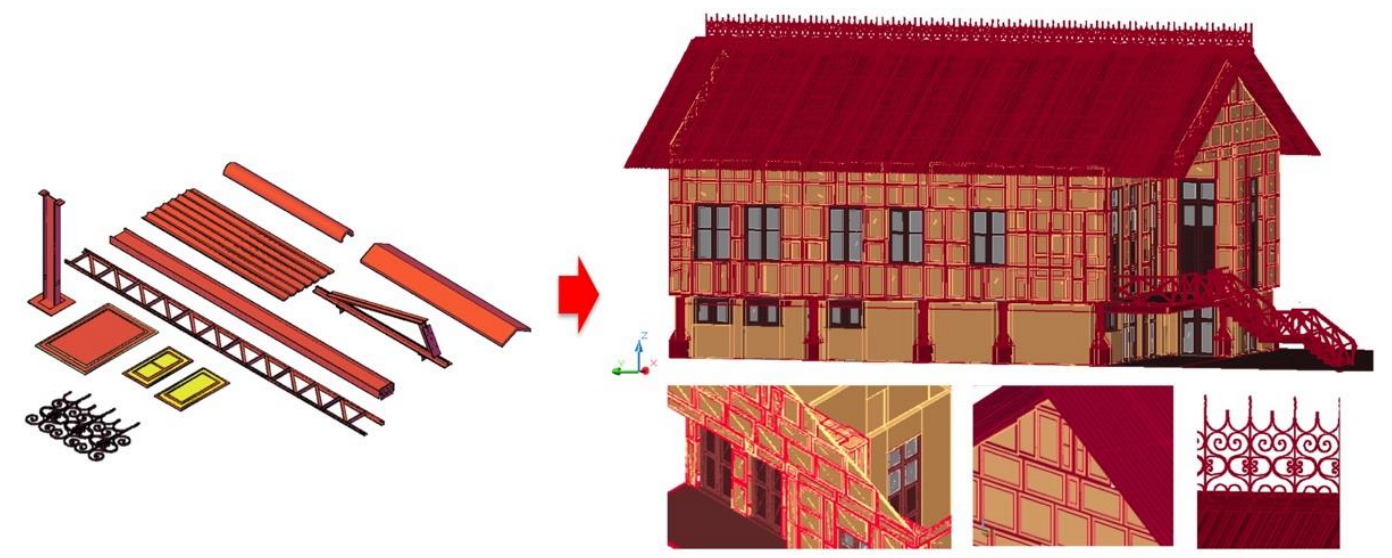

\section{CONCLUSÕES}

De maneira geral, pode-se aferir a viabilidade técnica de remontagem do chalé desmontado, ainda que a estrutura esteja incompleta, a partir dos resultados da pesquisa (Figura 9). 0 novo uso e local de remontagem deverá ser estudado de forma a valorizar essas estruturas e dar-lhe um protagonismo que reconheça sua raridade, tecnologias empregadas, a produção do conhecimento científico, a sua potencial capacidade de utilização e reinserção na paisagem urbana, aliando-se novas tecnologias da ciência da conservação que venham a enriquecer a estrutura arquitetônica e seu melhor aproveitamento público. 


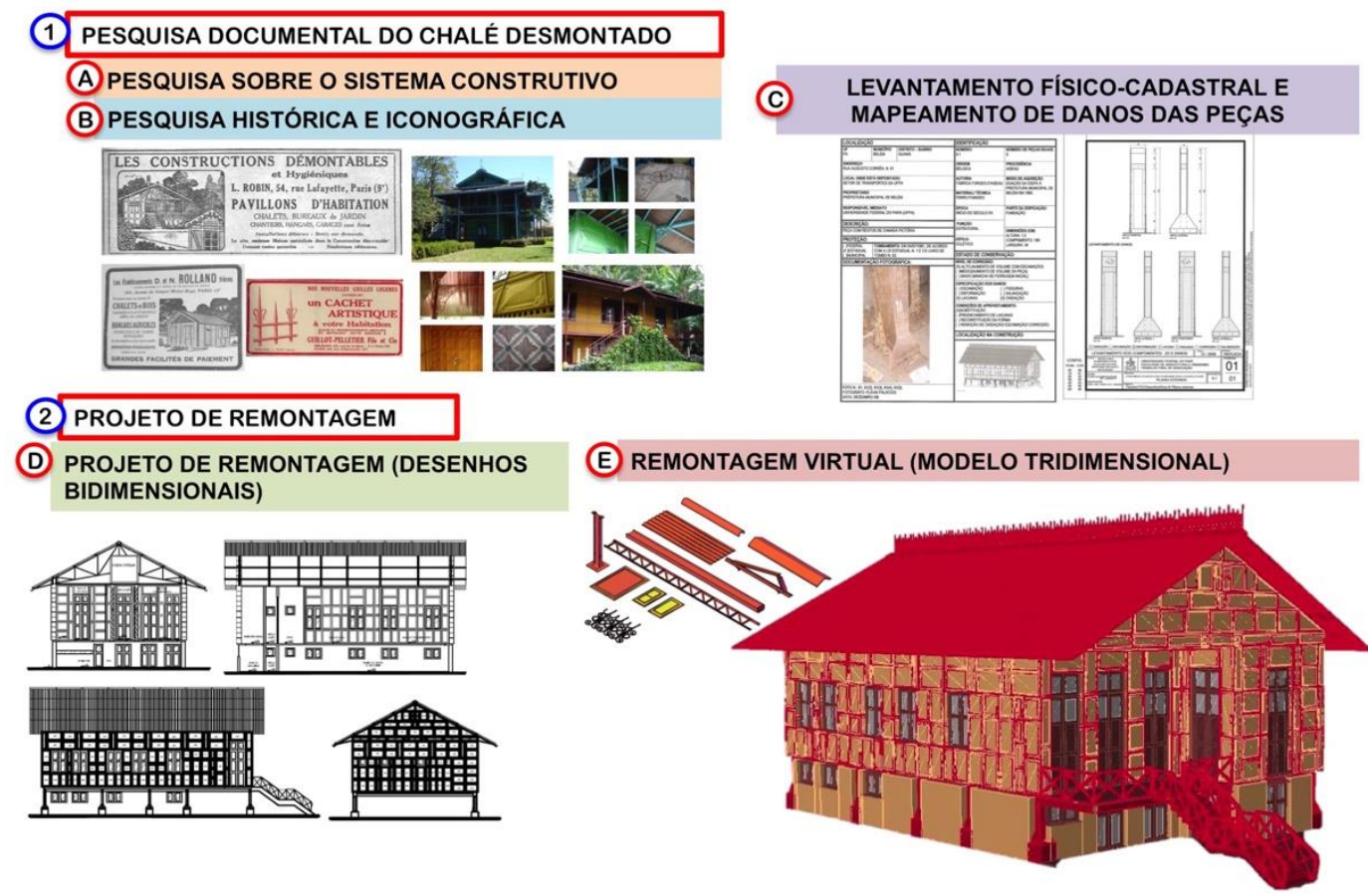

Figura 9. Ações aplicadas na documentação do chalé

Fonte: Elaborada pelas autoras

0 uso das tecnologias CAD nessa pesquisa foi ferramenta imprescindível, auxiliando na preservação da memória e demais ações (STYLIADIS, et SECHIDIS, 2011; GOMES, BELLON, SILVA, 2014; WILSON et al, 2017), e importante para a reconstituição virtual do edifício, ainda que atualmente não seja a mais moderna tecnologia, mas a disponível no momento do trabalho, já que a pesquisa não possuía recursos financeiros na época.

Sabe-se que há novas tecnologias aplicadas para a documentação mais eficiente do patrimônio histórico edificado, e na continuidade da pesquisa, inclusive em estudos de bens integrados metálicos em fachada e demais edifícios inteiramente metálicos, sentiu-se a necessidade de migrar para tecnologias mais contemporâneas tais como BIM, com a utilização do REVIT.

Todas as etapas desta pesquisa foram fundamentais para entender a concepção modular e estrutural dos edifícios do Sistema Danly, e também dos outros edifícios históricos metálicos de Belém, que vem sendo estudados, bem como balizar e subsidiar eventuais intervenções conservativas, restaurativas e de requalificação específicas para esse tipo de arquitetura.

O chalé desmontado é objeto de pesquisas desde 2007 pelo LACORE, e atualmente o foco é voltado para o aprofundamento de outras temáticas relacionadas à conservação e restauro do edifício, sejam de cunho teórico ou tecnológico. Entretanto, sabe-se da necessidade de atualização de alguns dados documentais para uma proposta de reabilitação, já que essa foi a primeira etapa da pesquisa, e o conhecimento acerca do chalé desmontado vem amadurecendo no decorrer dos anos.

Atualmente busca-se viabilizar a elaboração de plano de restauro, incluindo atualização da análise do estado de conservação das peças, análise estrutural, projeto de montagem, incluindo peças remanescentes e novas, e demais projetos complementares para a completa restauração, readequação e reabilitação do Antigo Chalé de Ferro da IOEPA, o chalé desmontado, atualmente sob guarda da Universidade Federal do Pará (UFPA). 


\section{Agradecimentos}

Agradecimentos à Universidade Federal do Pará pelo apoio na pesquisa desenvolvida, à Coordenação de Aperfeiçoamento de Pessoal de Nível Superior (CAPES) pela bolsa de mestrado da primeira autora, e ao Conselho Nacional de Desenvolvimento Científico e Tecnológico (CNPQ) pela bolsa de doutorado da primeira autora.

\section{Referências Bibliográficas}

BERNARDI, Leonardo; BUSANA, Maria Stella; CENTOLA, Vanessa; MARSON, Claudia; SBROGIÒ; Luca. The Sarno Baths, Pompeii: Architecture development and 3D reconstruction. Journal of Cultural Heritage, 40, p. 247-254, 2019. DOI: https://doi.org/10.1016/j.culher.2019.04.011. Acesso em 10 de agosto de 2020.

BRANDI, Cesare. Teoria da Restauração. São Paulo: Ateliê Editorial, 2004.

COSTA, Cacilda Pereira da. O Sonho e a Técnica. A arquitetura de Ferro no Brasil. São Paulo: Universidade de São Paulo, 2001.

DERENJI, Jussara da Silveira. Arquitetura do Ferro: Memória e Questionamento. Belém: CEJUP, 1993.

FONTINHA, Isabel Rute; SALTA, Maria Manuela. Componentes Metálicos na Construção Comportamento à corrosão e sua prevenção. Lisboa: Laboratório Nacional de Engenharia Civil, 2007.

GOMES, Leonardo; BELLON, Olga Regina Pereira; SILVA, Luciano. 3D Reconstruction Methods for Digital Preservation of Cultural Heritage: A Survey. Pattern Recognition Letters, 2014. DOI: http://dx.doi.org/10.1016/ j.patrec.2014.03.023. Acesso em 10 de agosto de 2020.

KÜLH, Beatriz Mugayar. Arquitetura do Ferro e Arquitetura Ferroviária em São Paulo - Reflexões sobre a sua Preservação. São Paulo: Ateliê Editorial, 1998.

KÜLH, Beatriz Mugayar. Preservação do Patrimônio Arquitetônico da Industrialização - Problemas Teóricos do Restauro. São Paulo: Ateliê Editorial, 2008.

O LIBERAL (Jornal). Inquérito vai apurar os danos do chalé de ferro. O Liberal, 06 de Abril de 1991.

OLIVEIRA, Mário Mendonça de. A documentação como ferramenta de preservação da memória. Brasília: IPHAN/ Programa Monumenta, 2008.

PALÁCIOS, Flávia Olegário. Antigo chalé da Imprensa Oficial do Estado do Pará: montagem, restauro e reutilização. 2009. 4.000f. Trabalho Final de Graduação (Graduação) - Faculdade de Arquitetura e Urbanismo, UFPA, Belém, 2009.

PALÁCIOS, F.O. Dos minerais aos materiais de arquitetura e processos de degradação: edifícios e ornamentos metálicos dos séculos XIX e XX em Belém do Pará. 2015. Tese (Doutorado em Geologia e Geoquímica) - Universidade Federal do Pará, Programa de Pós-Graduação em Geologia e Geoquímica, Belém, 2015.

PALÁCIOS, F.O. Estudo tecnológico do chalé da IOEPA: subsídios para a salvaguarda da arquitetura de ferro. 2011. Dissertação (Mestrado em Arquitetura e Urbanismo) - Universidade Federal da Bahia, Programa de Pós-Graduação em Arquitetura e Urbanismo, Salvador, 2011.

PALÁCIOS, F. O; ANGÉLICA, R. S; SANJAD, T. A. B. C. The Metal Alloys From the XIX Century and Weathering Action in the Mercado do Ver-o-Peso Building, Northern Brazil: Identification with the Usage of Laboratory Analysis. Materials Characterization, n. 96, p. 225-233, 2014. 
PONTES, Lilia Fonseca de Brito; REIS, Liana Magalhães; DUARTE, Lucia Montenegro. Chalé de Ferro. 1978. 32f. Trabalho Final de Graduação (Graduação) - Departamento de Arquitetura, Universidade Federal do Pará, Belém, 1978.

SARGES, Maria de Nazaré. Belém: riquezas produzindo a Belle Époque (1870-1919). Belém: PakaTatu, 2010.

SILVA, Geraldo Gomes da. Arquitetura de Ferro no Brasil. São Paulo: Nobel, 1986.

STYLIADIS, Athanasios D; SECHIDIS, Lazaros. Photography-based façade recovery \& 3-d modeling: A CAD application in Cultural Heritage. Journal of Cultural Heritage, 12, p. 243-252, 2011. DOI: doi:10.1016/j.culher.2010.12.008

VIÑAS, Salvador Muñoz. Contemporary Theory of Conservation. Oxford: ELSEVIER, 2005.

WILSON, Lyn; RAYLINSON, Alastair; FROST, Adam; HEPER, James. 3D digital documentation for disaster management in historic buildings: Applications following fire damage at the Mackintosh building, The Glasgow School of Art. Journal of Cultural Heritage, 2017. DOI: https://doi.org/10.1016/j.culher.2017.11.012. Acesso em 10 de agosto de 2020.

Flávia Olegário Palácios flaviaop@ufpa.br

Thais Alessandra Bastos Caminha Sanjad thais@ufpa.br 